This item was submitted to Loughborough's Research Repository by the author.

Items in Figshare are protected by copyright, with all rights reserved, unless otherwise indicated.

\title{
Cryptocurrencies from an Austrian perspective
}

PLEASE CITE THE PUBLISHED VERSION

https://doi.org/10.1007/978-3-319-75817-6_12

PUBLISHER

(C) Springer

VERSION

AM (Accepted Manuscript)

PUBLISHER STATEMENT

This book chapter was published in the book Banking and Monetary Policy from the Perspective of Austrian Economics [@ Springer International Publishing AG, part of Springer Nature]. The definitive published version is available at: https://doi.org/10.1007/978-3-319-75817-6_12.

\section{LICENCE}

CC BY-NC-ND 4.0

\section{REPOSITORY RECORD}

Milne, Alistair. 2018. "Cryptocurrencies from an Austrian Perspective". figshare.

https://hdl.handle.net/2134/36923. 


\title{
Cryptocurrencies from an Austrian perspective*
}

\author{
Alistair Milne ${ }^{+}$ \\ Book chapter version. May $25^{\text {th }}, 2017$
}

\begin{abstract}
This chapter sets out a proposal for fundamental reform of monetary arrangements, using the technology of cryptocurrencies to move all bank and fiat money off balance sheet onto a single state sponsored mutual distributed ledger. This helps achieve monetary outcomes desired by the Austrian school of economics: allowing an almost complete withdrawal of the state from the provision of money and credit and reducing the need for bank regulation, lender of last resort and bank bail-out. (76 words)
\end{abstract}

JEL codes B53, E42, G21

Keywords: 100-percent reserved banking, Austrian school, bank payments, bank regulation, bank reserves, Bitcoin, blockchain, central banking, central counterparties, the Chicago plan, clearing and settlement, credit money, cryptography, commodity money, decentralised counterparties, digital currency, distributed ledgers, electronic currency, fiat money, fiduciary media, financial crises, financial stability, fintech, fractionally reserved banking, funding liquidity, the gold standard, laissez-faire economics, lender of last resort, macroprudential, maturity mismatch, medium of exchange, monetary arrangements, monetary policy, monetary technology, money markets, money substitutes, mutual payments networks, narrow banking, payments infrastructure, payments systems, ring-fencing, systemic risk, Volcker rule

Citation: Milne, Alistair, Cryptocurrencies from an Austrian Perspective (April 17, 2017). https://ssrn.com/abstract $=2946160$ or http://dx.doi.org/10.2139/ssrn.2946160

\footnotetext{
${ }^{*}$ On being invited to write this chapter I first wrote a lengthier and more technical discussion of cryptocurrency technologies and their use to reduce the role of both the state and banks in money creation. That paper is available on SSRN at https://papers.ssrn.com/sol3/papers.cfm?abstract id=2946160. My intention is, eventually, to write a book length treatment of the issues raised by this investigation. I am indebted to the support of the Department of Banking and Finance at Monash University Business School during a period of study leave when this chapter was written and for comments from Denys Firth, Charles Goodhart, David Mayes and George Selgin and from a number of seminar presentations.

† Loughborough University, UK; email: a.k.I.milne@lboro.ac.uk
} 


\section{Contents}

1. Introduction: the challenge of restoring free markets in money and credit.................................. 3

2. Distributed ledger money and Austrian policy objectives....................................................... 6

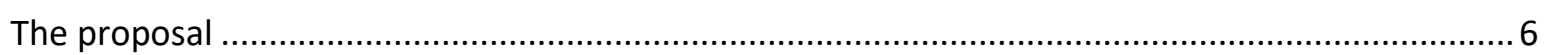

A reflection on the changing nature of the medium of exchange .............................................. 8

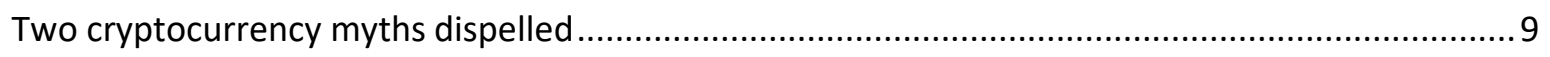

How placing deposit money on a mutual distributed ledger supports Austrian ideas .....................12

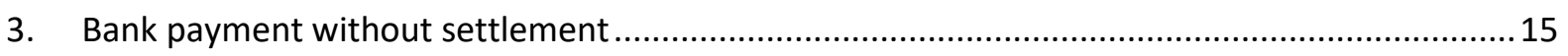

The evolution of bank payments and settlement: a short historical review ...................................15

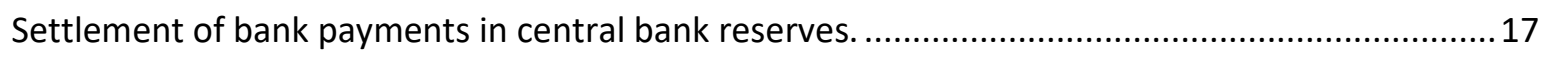

Figure 1: fractional reserved banking with central bank settlement .......................................... 18

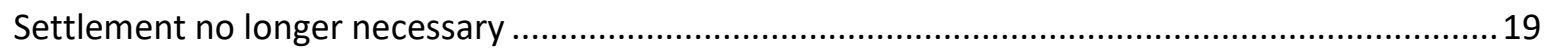

Figure 2: Fractional reserved banking without settlement using distributed ledger ...................19

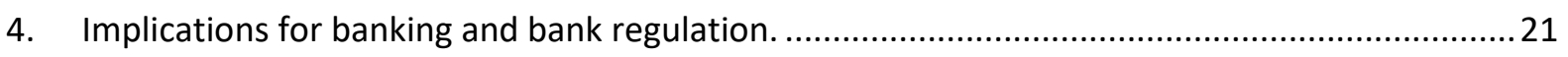

The triple lock: ensuring repayment of bank money on the ledger ..............................................21

Applying $x$-per cent reserving to limit fractionally-reserved monetary deposits ...........................22

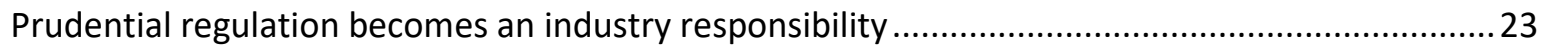

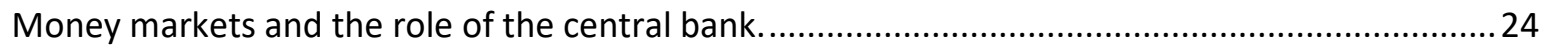

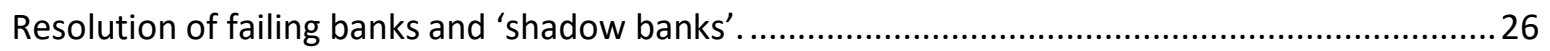

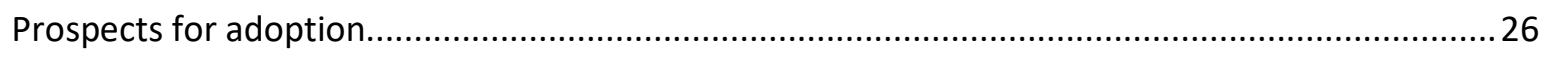

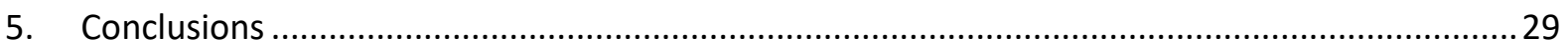

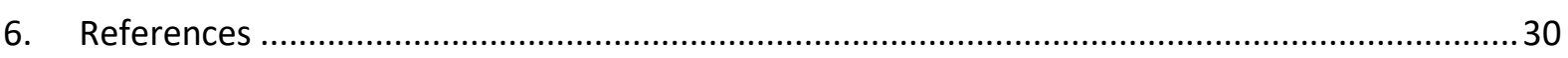




\section{Introduction: the challenge of restoring free markets in money and credit}

Austrian economics provides fundamental but too often ignored insights into the challenges of monetary and macroeconomic policymaking. The Austrian theory of the business cycle offers a persuasive account of the genesis of the 2007-2008 crisis: it was made possible by the reliance of central banks worldwide on the reduction of short term rates of interest to promote private sector spending. This encouraged an unsustainable expansion of money and credit. The only substantive difference from previous financial crises, something that allowed the preceding credit boom to proceed for so far and so long, was that instabilities arising from maturity mismatches appeared in new and therefore hidden variants, through money market funding of mortgage backed securities and other structured credit assets. Austrian economics also provides a valuable explanation of previous episodes of global economic instability, for example the breakdown in the early 1970s of the post-war Bretton-Woods fixed exchange rate system based on a gold exchange standard as a consequence of insufficient discipline on US monetary creation.

Austrian economics is also the only free-market orientated school of thought drawing full attention to the deficiencies of the global policy response since 2007-2008. ${ }^{1,2}$ Central banks and governments around the world have mitigated the impact of the crisis on output and employment, providing more than $\$ 10$ trillion dollars of financial support to prevent bank failures, cutting short term interest rates for all the major currencies close to zero and engaging in a sustained and aggressive fiscal expansion that has more than doubled the ratio of public sector debt to GDP.

These measures may have been effective short-term palliatives, but they have done little to deal with underlying causes. While substantial increases in regulatory capital requirements and a wide range of other regulations have reduced tax-payer exposure to banking risks, investors have been left in little doubt that they will be protected once again should the entire financial system once again be threatened. The resumption of growth in the advanced economies is based as before on credit creation and maturity mismatch. The mispricing of assets and misallocations of capital evident before the crisis have continued, in many cases becoming even more marked. Economic expansion has been much stronger than was generally expected in the 18 months following the collapse of Lehman brothers, but this recovery has not been strong enough to allow a winding down of fiscal expansion. A policy of temporary 'pump priming' has turned into a policy of permanent and unsustainable fiscal deficits.

These deficiencies seem to make a new and potentially even more serious global economic crisis inevitable. The uncertainties are about its timing and form. Perhaps there will be renewed fiscal and monetary expansion in response to the next economic downturn, postponing the inevitable adjustment for a number of years further down the road? Perhaps the crisis will emerge as a collapse of confidence in government liabilities, including central bank money, rather than in banks and secured money market instruments? Another crisis is looming, we just do not know when it will happen or how it will emerge.

\footnotetext{
${ }^{1}$ Some flavour of the reaction of the Austrian economists and their criticisms of government bailouts at the time of the 2008 crisis can be found at https://mises.org/library/bailout-reader .

${ }^{2}$ Heterodox post-Keynsian economics in the Minskian tradition provide another critique of the mainstream policy consensus, agreeing with Austrian school thinking that current policies will lead to an eventual and even more serious global economic crisis. This analysis though is predicated on the assumptions of inherent flaws in the market economy and therefore advocates an even more radical replacement by the state of market mechanisms and market allocations of resources than has already taken place to date.
} 
As discussed in other chapters of this book, Austrian thinking offers many policy recommendations that can help avoid such an undesirable outcome. There is though a barrier to their adoption, they are still largely perceived as politically unacceptable. To take one example, consider a move to 'free banking': with freedom to establish banks; with regulation limited to the same kind of regulatory framework that applies to most other industries -the rigorous application of the framework of law to enforce contractual agreements, prevent frauds and stop the sale of unsafe or misleading products and services - and leaving banks that are unable to fund themselves to face the same disciplines as other commercial organisations, having to suspend operations and wind themselves down. This can be expected to result in much safer and sounder banking, with limited use of unstable fractional reserving. Nevertheless, in the wake of the crisis and the general blame cast (with some justification) on irresponsible bankers, no political programme can be realistically expected to prioritise such a reform. An outcome of the global financial crisis is instead that money and credit are nowadays seen more than ever, both in the mind of the public and politicians that seek their votes, as a state responsibility.

This chapter offers a novel technological perspective on the challenge of restoring public faith in the effectiveness of market mechanisms in the provision of money and credit. The technology concerned is the radical decentralisation of payments, without any need for a state controlled monetary base or centralised settlement, made possible by using distributed ledgers (or 'blockchain'), the shared transaction records that underpin cryptocurrencies such as Bitcoin. It is proposed here that all money - both state supported fiat money and money issued by banks to finance lending - should be placed on a single distributed ledger. This can then support many of the key Austrian proposals for monetary arrangements.

This proposal set out here may be regarded as a rather 'impure' version of Austrian thinking. It is not obviously the arrangement that would emerge from a voluntary agreement amongst citizens and businesses in the absence of state intervention. An important co-ordinating role is still envisaged for the state, sponsoring the establishment of the distributed ledger for both bank and fiat money. Still, even if this proposal does not go as far as many proponents of Austrian policy ideas would like, it has - it will be argued - the key advantage of greater potential political acceptability.

It requires little or no change in the day to day experience of payments and borrowing by households and companies. The panoply of bank regulations does not have to be torn down from the outset, they can be removed gradually. Banks cannot object (as they do to proposals for $100 \%$ reserving) that the ledger makes it difficult for them to extend credit. It also makes the relationship between banks and customers and banks much more transparent than at present. No longer are banks engaged in an arguably illegal contractual engagement by holding customer money as withdrawable deposits rather than risky investments, deposits whose withdrawal they cannot guarantee in all circumstances, hence helping promote the political case for private sector creation of money and credit.

The Austrian perspective as developed in the present chapter is not one which views the explosion of competing private sector open source decentralised digital monies (Bitcoin, Ethereum, Ripple, NEM, Monero and several hundred more) as a practical implementation of Hayek's ideas on the denationalisation of money - i.e. an evolution in which money is supplied by competing private sector providers seeking to establish their credibility with the public rather than by the state. This 
perspective is endorsed by many working or commenting on the development of new digital currencies; ${ }^{3}$ and explored by Chikako Nakayama in the preceding chapter of this book.

These two perspectives, as set out in our two chapters, are different but not inconsistent. Should the ideas put forward in this particular chapter be put into effect, with fiat and bank money all placed on a distributed ledger, this does not create any additional barriers to the launch of a private sector cryptocurrency also issued on a distributed ledger which competes with existing state supported fiat money. A competing private sector cryptocurrency might also - as envisaged for the state sponsored cryptocurrency described here -- allow banks to create money through a securitisation of loans onto their own ledger. State and private cryptocurrencies could still compete if there is demand for using both from households and companies.

The chapter is organised as follows. Section 2 summarises the proposal and explains how it supports Austrian proposals on money and credit. Changing banking arrangements and payments technologies over the past two centuries have altered perceptions about the nature of money - with the understood and accepted medium of exchange in the modern economy evolving to become transaction balances held with banks. This proposal for shifting these bank transaction balances onto a mutual distributed ledger reverses the resulting encroachment of banks and the state on the supply of money. The next two sections develop the proposal in more detail. Section 3 examines the arrangements for execution and settlement of payments as they have evolved today, requiring central banks to provide reserves as a settlement asset and a permanent commitment to liquidity support to commercial banks and money markets in order to avoid interruption in the flow of money and payments. It then discusses the changes to these arrangements required for placing fiat money and bank-money on a single distributed ledger and hence obviating the need for settlement in central bank reserves or unconditional central bank support for the banking system. Section 4 discusses the implications for bank regulation and the provision of money and credit. It also considers the political acceptability of the proposal. Section 5 concludes.

\footnotetext{
${ }^{3}$ For example (Koenig 2015), an entertaining but rather proselytising introduction to Bitcoin and its supporting Blockchain ledger, explicitly invokes the link to Austrian economics in both title and text. His book - as well as describing the technology for non-specialists and documenting some of the viewpoints of those involved in the 'Bitcoin movement' - espouses the radical position that these technologies will prove to be a more profound technological development than even the internet, replacing the malign role of the nation state in both economics and politics. A wealth of websites and internet forums share similar viewpoints.
} 


\section{Distributed ledger money and Austrian policy objectives.}

This section outlines the proposal of this paper and explains how it can achieve Austrian monetary policy objectives.

\section{The proposal}

The proposal itself is simple and can be presented in general terms without reference to cryptography or information technology. It has the following elements:

- Banks create monetary deposits as they already do today, but all commercial bank money and central bank money now takes the form of an electronic equivalent of a central bank note, i.e. a decentralised money transferred directly from one holder to another.

- This decentralisation is achieved by having both commercial banks and the central bank issue their money on a "mutual distributed ledger", a universal but decentralised record of the issuance and transfer of all money used in exchange (including paper notes and token coin whose issue is fully backed against the ledger). ${ }^{4}$

- As a result of this decentralisation there is no need for subsequent settlement using central bank reserves and no longer any distinction between (in Austrian terminology) the medium of exchange and money substitutes or (in conventional monetary vocabulary) outside and inside money.

- Deposits that are not on the ledger but promise immediate redemption on demand into ledger money are required to state explicitly that they are loans at risk of potential temporary suspension or permanent default, should the issuer not have a sufficient reserve of ledger money to redeem as promised.

- All payment instruments (e.g. cards, credit transfers, automated clearing such as direct debits and standing orders) become mechanisms for instructing transfers of ledger money.

- The difference between commercial bank issue and fiat issue by the central bank is that fiat issue is permanent and cannot be withdrawn; commercial bank issue is only temporary, in the form of a short term securitisation of future anticipated repayments, on loans of good credit quality over the short to medium term.

- Two mechanisms ensure repayment and prevent an inflationist exploitation of money issue:

(a) repayment onto the ledger is covered by a 'triple lock' - if the bank customer does not repay the loan to the ledger then the bank that provided the loan repays; if the bank does not repay then the entire banking industry makes the repayment in proportion to their outstanding money they have issued on the ledger at the time the initial loan is made. The ledger becomes a creditor on the bank, with a claim prior even to the tax authorities, repaying other banks as this claim is recovered.

(b) the bank money so securitised is 'overcollateralized', i.e. for each $€ 100$ of loan principal pledged as repayment, the bank must provide $€ x$ in upfront money to the ledger (i.e. the new money created is only $€ 100-x$ of the principal value of the pledged loan). This " $x$-percent reserving" allows an effective partial implementation of the 100-percent reserving advocated by many Austrian thinkers.

\footnotetext{
44 'Mutual distributed ledger' is a coinage of my co-author Michael Mainelli. Describing distributed ledgers as mutual highlights a key feature, the absence of any trusted central authority, which is both a strength (supporting resilience, immutability) and a weaknesses (creating challenges of governance).
} 
- Bank transactions deposits are no longer bank liabilities, rather they are transaction or 'wallet' services providing access to payment instruments and accounting statements for holders of ledger money; a payment instruction for any supported instrument can only be carried out if there is sufficient ledger money to fulfil the instruction when it is made.

This proposed arrangement goes well beyond the discussions of possible central bank issue of cryptocurrency made, at least to date, by a number of central banks worldwide. ${ }^{5}$ It is not just the issue of a virtual central bank liability, the internet equivalent of a central bank issued banknote, or the use of distributed ledger to support a virtual currency that is completely backed by central bank money. ${ }^{6}$ It is a complete redesign of the arrangements for holding and paying fiat and bank money with profound implications for the relationship between banking and the state.

Most importantly, it allows the banking industry to take final responsibility for repayment of temporary creation of money on the ledger. Hence authorisation for banks to issue money on the ledger and to monitor the quality of the credit assets pledged can become an industry rather than a state responsibility.

What role is played in this schema by information technology and cryptography? The distributed ledger technology developed for cryptocurrencies such as Bitcoin provides the essential decentralised immediate real time accounting framework that makes this schema workable. In principle, while it could be put into effect with pre-existing technologies, this would have required a central agency to maintain records of transactions and money holdings and approve payments only when the holder has money to pay. Before distributed ledger technologies were available there would then have been serious concerns about the confidentiality, operational risks and operating costs of such an arrangement - putting the entire nation's money onto a centralised computer system that might be hacked or go offline is not an attractive prospect.

Utilising distributed ledger technologies deals with these concerns. The supporting cryptography allows secure and fully flexible permissioning for both the making of payments and the observation of transaction records. Having many copies of the transaction record eliminates operational risks (one node can fail but the network is extraordinarily robust). Distributed ledgers are also entirely automated, so this schema can operate at very low cost (fractions of a cent per transaction), costs which can be easily shared by governments, participating banks and holders of money, based on their issuance and holding of money and number of transactions.

Note, finally, that the resulting state sponsored cryptocurrency, unlike the 'unpermissioned' cryptocurrencies such as Bitcoin, cannot be completely anonymous: identity is required for

\footnotetext{
${ }^{5}$ Central banks have naturally been paying close attention to the technologies of virtual money, see for example (Ali et al. 2014b; Ali et al. 2014a). The central issue in these discussions has been whether there is demand for holding a central bank issued crypto-currency i.e. something like the suggested Fedcoin outlined by (Koning 2014; Andolfatto 2015). Demand is uncertain, users may prefer the guaranteed anonymity of notes and coin and there are already effective means for carrying out most online monetary transfers using bank money. For further discussion see (Fung \& Halaburda 2016). Bank of Canada and Bank of England research on this topic - can be accessed through their webpages, various postings on http://www.bankofcanada.ca and http://www.bankofengland.co.uk/research/Pages/onebank/cbdc.aspx. Sveriges Riskbank have also announced they are investigating possible issue of digital currency (Skingsley 2016).

${ }^{6}$ Such as the Utility Settlement Coin or Tibado described above, or the Monetary Authority of Singapore project working with R3 and a consortium of banks to develop a fully centrally backed virtual currency on distributed ledger that can be used in securities settlement and cross-border payments (on this see Monetary Authority of Singpore 2017).
} 
repayment; law enforcement should be able to trace payments with appropriate court permissions; some further limitations on anonymity may be justifiable.

\section{A reflection on the changing nature of the medium of exchange}

A central part of Austrian monetary thinking is the distinction between the medium of exchange and fiduciary media (or 'money substitutes') and the social and technological changes in money and banking of the past two centuries. It is argued here that modern monetary arrangements have evolved so that today the medium of exchange is no longer commodity or fiat money but rather bank transaction deposits. Therefore the implementation of Austrian monetary arrangements requires reducing the role of both the state and of state supported banks in the determination of the volume of bank transaction deposits.

Austrian monetary analysis frequently refers back to the early $19^{\text {th }}$ century debates between the banking school and currency school in the UK and the contemporaneous arguments for freebanking. ${ }^{7}$ The currency school arguments of McCulloch, Lord Overstone, Torrens and others that stressed the instability resulting from bank money creation won the battle for political opinion but lost the war. The 1844 UK banking act introduced strict limitations on the issue of bank notes on currency school lines, denying the right of issue to new banks established after the act, requiring all additional issue by the Bank of the England and Scottish banks to be backed $100 \%$ by gold reserves, and preventing any additional issue by other existing banks. But as pointed out by (Von Mises 1953) and many other Austrians, the UK legislation did nothing to limit the creation of bank transaction deposits which served as money substitutes through the increasing use of the cheque as a means of payment. The following century saw a massive expansion of chequeable deposits. Cheque payments came to replace gold coin and bank notes as the dominant payment instrument for larger value payments in industry, trade and finance, and the gold sovereign was withdrawn from circulation in 1914.

Austrian thinking argues that the social institution of money is not a creation of the state. In the absence of government action economic incentives still ensure the establishment of a medium of exchange to support trade between strangers. This view seems indisputable. While the historical record is of course open to interpretation, there being few examples of expansion of trade without some accompanying political developments, examples such as the widespread use of silver as a medium of exchange in the earliest international trade between the fertile crescent and the Mediterranean region or of Cowrie shells in trade across much of Africa and Asia, without any accompanying political interaction, attests to the fundamental validity of this Austrian view.

The emergence of money as a social institution without the requirement of state support does not however mean that the state has no influence on monetary arrangements; or that the institution of money does not itself evolve over time in response to either social or technological change. This is a particular challenge for the Austrian distinction between the medium of exchange - the socially accepted form of money in exchange - and 'money-substitutes' or fiduciary media, claims which are redeemable on demand in the medium exchange and which are used as a replacement for the medium of exchange for making payments. Examples of fiduciary media include both privately issued bank notes and transferable bank deposits.

Because money is a social institution, there is nothing to prevent a psychological and cultural change in which banking deposits have become transformed, in the minds of those who hold them, from being redeemable claims on money to being money themselves. Nowadays, even when money is

\footnotetext{
${ }^{7}$ See also (Schwartz 1989) for a succinct review of these controversies.
} 
withdrawn from bank accounts it either takes the form of central bank notes or of state issued token coinage. Not only has the past century seen a shift from widespread use of gold as a monetary standard to a fiat money standard, this has been accompanied by an equally fundamental change in the medium of exchange. This arguably is now money in a bank account, in turn leading to the political imperative to provide deposit insurance and the bank safety net so that all privately held bank deposits, whether transaction or savings deposits, are good money.

As the medium of exchange has evolved in the minds of users, no longer taking the form either of gold or state liabilities and instead becoming liabilities of banks, there has been an accompanying blurring of the distinction between money held in a bank e.g. in a safe deposit and a loan of money to a bank. The public has come to perceive all forms of retail banking deposit alike - whether immediately withdrawable without penalty, withdrawable with some loss of return, or term deposits withdrawable only at notice - as money in the care of the bank not as loans to the bank. Similar expectations extended even into wholesale money markets, with expectations that in the event of widespread threat of default on money market obligations the central bank will provide the necessary liquidity to ensure repayment, using the assets financed out of retail deposit taking as collateral.

We have a vicious circle (a 'positive feedback' in engineering terms) of cause and effect in which the perception that bank liabilities are themselves the medium of exchange drives a range of state protections for banking and these state protections in turn reinforce the perception that bank liabilities are indeed the medium of exchange. This in turn supports the expansion of state support, through state backed deposit insurance and the implicit bank safety net and the large scale expansion of banking balance sheets. The outcome is an overexpansion of banking assets and liabilities that in turn threatens the viability of the private enterprise economy.

A solution to this incursion of the state into what are naturally private concerns, perhaps the only solution that would appear acceptable politically, is to work with the grain of this newly emerged social institution, to accept that transferable bank deposits function directly as the medium of exchange, but also sharply differentiate these deposits from other bank liabilities whether retail or wholesale that are merely promises to repay the holder in terms of the medium of exchange. The distributed ledger proposal of this chapter utilises the new cryptocurrency technologies to achieve this end.

\section{Two cryptocurrency myths dispelled}

Before discussing in detail how distributed ledger money, sponsored by the state, can help achieve Austrian policy objectives, two 'myths' about cryptocurrencies should be dispelled. ${ }^{8}$ One is that the suggestion that an unpermissioned open-source cryptocurrency could serve as a monetary standard outside of state control. A second is that current unpermissioned cryptocurrencies could easily compete with established fiat currencies for widespread use in everyday domestic exchange.

Arguments for a cryptocurrency standard circulate frequently in developer communities, with statements along the following lines: a cryptocurrency such as Bitcoin is, by construction, in limited supply and therefore - because it is also durable and divisible - shares many features with gold. This analogy is one reason why the term 'mining' was applied to the cryptocurrency proof of work used in Bitcoin to validate payments, a service rewarded with newly created currency. ${ }^{9}$ Because of this

\footnotetext{
${ }^{8} \mathrm{~A}$ fuller discussion of the points made in this subsection can be found in the supporting working paper.

${ }^{9}$ The original white paper describing the Bitcoin protocol (Nakamoto 2008) contains a strong statement of the desirability of having money whose supply is not controlled by the state, but instead determined by a peer-to-
} 
analogy with gold, so it is claimed, a cryptocurrency in limited supply can be a trustworthy replacement for unsound state fiat currencies.

This possibility, that the medium of exchange could be a cryptocurrency, is sympathetically but critically discussed by (Selgin 2015). He views cryptocurrencies such as Bitcoin as a 'synthetic commodities' i.e. like real commodities such as gold or silver the available stock cannot be increased at will by an issuing authority, but unlike gold or silver cryptocurrencies they have no value in any alternative non-monetary use. There are examples of synthetic commodities which have come to be accepted as media of exchange and successfully avoided the inflationary bias of fiat currency. ${ }^{10}$ Still, as Selgin admits, the state adoption of a cryptocurrency whose quantity is outside of state control as a monetary standard seems unlikely, and the possibility of privately created synthetic commodity money supplanting fiat money seems remote - at best it would seem that they might come to be widely accepted in exchange alongside fiat money. He concludes that 'the possibility of monetary stabilization achieved by means of a synthetic commodity standard remains as hypothetical as it is tantalizing'.

Another possibility might be fixing the value of fiat currency against a well-established cryptocurrency perhaps Bitcoin, requiring the central bank to build up its own reserve of the cryptocurrency, but this could not be seriously considered until the cryptocurrency was already widely used in exchange and from this had achieved comparative stability of value against fiat currency. ${ }^{11}$ The record of Bitcoin and of other currencies demonstrates that while cryptocurrency has appeal as a relatively risky financial investment, at least on a modest scale, cruyptocurrency use in exchange is unlikely to achieve any significant traction.

Demand for Bitcoin as a store of value is driven by a number of special factors including: technophile's appreciation of the underlying software; the appeal of private cryptocurrencies to individuals seeking to counteract the extraordinary growth in the power of the state in the past century, or to those with the more extreme libertarian views of the 'cryptophunk' movement, seeking to exploit cryptography to establish an entire realm of social and economic exchange beyond the reach of the state. There is also a fundamental demand driven by the practical challenges of avoid currency controls and other financial regulations or use in illegal transactions. ${ }^{12}$

peer network. This white paper is also the source of the term 'mining' for proof of work rewarded by issue of cryptocurrency.

${ }^{10}$ As an example of a synthetic commodity money Selgin describes the case of the so called Kurdish Swiss Dinar, which circulated in Iraqi Kurdistan from 1993 to the US coalition invasion of Iraq in 2003. It had value in exchange even though it was governed by no monetary authority, was not legal tender and was not accepted as payment by Iraqi public institutions. Unlike the official Iraqi dinar the Kurdish Swiss Dinar proved immune from the large scale loss of value through inflation under the Saddam Hussein regime, its exchange rate against the dollar was stable and supported by the absolute fixity of its supply (unlike the official Iraqi dinar no new Kurdish Swiss Dinars could be printed).

${ }^{11}$ This relates to the long standing discussion in Austrian monetary economics of difference between the perceived stability of the gold standard proper and the evident instability of the gold-exchange standards established in the 1920s and then again under Bretton-Woods. The stability of gold standard proper is seen by many Austrian economists as resting on the widespread use of gold in direct exchange, e.g. through circulation of gold coin, suggesting that a prerequisite for the use of cryptocurrency as a monetary standard is the widespread use of the cryptocurrency in exchange.

12 See (Dowd 2014) for discussion of the demand for holding and using cryptocurrencies and other alternative private currencies. 
Cryptocurrencies has one advantage over previous independent monies which have attracted a hostile reaction from state authorities, closing down many of the most successful examples. ${ }^{13}$ The combination of an anonymous peer-to-peer exchange and the protection of identity using cryptography make it relatively difficult to prevent cryptocurrency transactions. The built-in quantity limitations on cryptocurrencies also provide a more credible foundation for competition in currencies than basing these on privately issued commitments to exchange in terms of the value of real commodities. ${ }^{14}$ For all these reasons cryptocurrencies now seem to be permanently established as alternative financial assets.

Despite this initial success, the volatility of pricing and limitations of both technology and governance suggest that no unpermissioned, open-source cryptocurrency can ever capture a major share of payments activity from established fiat currency instruments, whether these are using notes and coins or transferring bank issued fiduciary media. The great fluctuations of Bitcoin pricing mean that it is rather impractical to set prices or write debt contracts in BTC (the Bitcoin unit of account), at best there can be live updating of BTC prices for immediate transactions based on the latest current exchange rate into fiat currency. Where BTC is accepted in payment for goods and services it is almost always rapidly exchanged for conventional nation state currency, so Bitcoin is then serving merely as a payment instrument - like Paypal - not as an alternative medium of exchange.

There are other potential problems with Bitcoin. There are substantial capacity problems in the Bitcoin network that remain far from resolved a year and a half after there were first widely discussed amongst network participants. The totally decentralised Bitcoin governance may prevent a satisfactory resolution ever emerging. It is also far from clear that its relatively costly 'proof of work' can be sustained when the creation of new Bitcoins to reward miners is reduced and eventually ceases.

These practical challenges highlight a more general difficulty of unpermissioned open-source cryptocurrency networks, their lack of governance mechanisms to cope with change. The lack of institutional structure also creates other inherent problems. For example it is not possible to institutionalise reversal of payments - in contrast to the established payment schemes such as Visa or Mastercard, again substantially limiting use in everyday exchange. This is a consequence of the unpermissioned structure with no real world identity, if identities were known it would be easy to establish mechanisms for payments reversal.

Finally, if contrary to this analysis, widespread adoption of unpermissioned open-source cryptocurrencies was to emerge, this would certainly be accompanied by heavy regulatory intervention to control supporting services such as exchanges and wallets, to prevent their use for illegal purposes or evasion of tax. This would be a further heavy 'headwind' against their widespread use.

All this indicates that the future of cryptocurrencies in the medium to long term will belong to permissioned private sector alternatives -supporting much quicker and more resource efficient processing with more flexible and practical governance that adapts to changing economic and business circumstances.

\footnotetext{
${ }^{13}$ See (Dowd 2014) for discussion of the closure of both the Liberty dollar and e-gold by US authorities.

${ }^{14}$ See (White 2014) for elaboration of this point and references to earlier work of White and (Taub 1985) on on the lack of credibility of a private currency pegged to a commodity index.
} 
This though is a quite different model, permissioning means also a need for control of identities and therefore integration into existing banking networks based on fiat currencies; so the outcome is not separate competing currencies but just separate competing means of payments. Such developments may effectively challenge the market power of banks in payment and transaction services but they are not a fundamental change to monetary arrangements. ${ }^{15}$ The main exceptions where unpermissioned open-course cryptocurrency may continue to develop are those countries where governments seek to assert control over economic and social activity, through controls on foreign exchange and other regulatory limitations on financial transactions. There unpermissioned cryptocurrency are likely to continue to be attractive as unregulated and unregulatable alternatives to repressed domestic and international payments.

\section{How placing deposit money on a mutual distributed ledger supports Austrian ideas}

Reading the Austrian contributions to monetary analysis, four policy ideas standout: ${ }^{16}(\mathrm{a})$ an underlying monetary standard in which the supply of the medium of exchange is based on a commodity or other substance in limited supply (the classical gold standard is one possibility, a cryptocurrency standard may be another); (b) 'free banking', with minimal limits on the establishment of banks and market discipline limiting the production of money and fiduciary media, possibly with no central bank at all and possibly with competition amongst currencies; ${ }^{17}$ (c) limits on the production of fiduciary media (financial claims such as fractionally reserved bank deposits that are readily accepted in payment and immediately redeemable for the medium of exchange); (d) avoidance of all forms of state subsidy and support for banks so their shareholders not taxpayers bear the costs of bank failure. This subsection argues that placing bank transactions and fiat money on a mutual distributed ledger provides a practical means of pursuing all four of these policies.

These policies have remained largely outside mainstream debate not because of disagreement about goals of economic policy but because Austrian policies have been viewed as unrealistic and impractical. The difference of view is though largely about means not about ends. Austrian economists have supported the restoration of the gold standard not as an exercise in nostalgia, but rather because they have seen it as the flawed but only truly effective tool for limiting state creation of money. ${ }^{18}$ They propose free banking and avoidance of state subsidy because deposit insurance, central bank liquidity support and 'bail out' of banks encourage risk-taking and neglect of the responsibilities of risk-management. They propose limits on the creation of fiduciary media i.e. bank deposits or other private sector liabilities that serve as money in order to prevent unsustainable private sector credit expansions (nowadays such restriction has become very mainstream, viewed as part of the 'macroprudential' toolkit, though as a form of state intervention this is not endorsed by all Austrian thinkers).

This subsection argues that, with the distributed ledger proposal of this chapter, all four of these policy ideas become more practical and therefore politically acceptable.

\footnotetext{
${ }^{15}$ For discussion of the competition implications of new payments technologies see (Milne 2016)

${ }^{16}$ Appendix B to the supporting working paper https://papers.ssrn.com/sol3/papers.cfm?abstract id=2946160 provides a fuller review of Austrian views on monetary arrangements.

17 (Hayek 1978; Hayek 1979) proposes removing government monopoly on the supply of money and having instead only private produced currencies, competing for the trust of the public and each trading at different market determined values; but this was a relatively late contribution within the Austrian School, a consequence in part of Hayek coming round to the view that restoration of the Gold standard was not possible. ${ }^{18}$ Von Mises and Hayek were not slow to recognise the costs and disadvantages of using gold as a monetary standard. For example Hayek writes: 'In a securely established world state with a government immune to the temptations of inflation it might be absurd to spend enormous effort in extracting gold out of the earth if cheap tokens would render the same service as gold with equal or greater efficiency.' (Hayek 1937, pg 405)
} 
(a) an underlying monetary standard in which the supply of the medium of exchange is based on a commodity (more specifically gold).

The case for the restoration of the classical gold standard need not be argued here. The mainstream consensus view is that the costs of such a policy substantially outweigh the benefits. Still it is clear that the mutualised monetary ledger proposed here could be the first step towards a full restoration of the classical gold standard, if that was so desired. The ledger would be legally required both to back the state issued money on the ledger with gold and to freely buy and sell the state issued money against gold in the open market at a defined price (carefully set at the outset to avoid severe misalignment of exchange rates against other countries also on a gold standard). Since all money would then be either gold or commodity backed - or temporarily issued bank supported fiduciary money - this would be a major step towards restoring the use of what would effectively be gold, albeit in a digital certificate form, in day to day transactions.

Such a standard could also conceivably, with all money on a distributed ledger, be developed along the lines first proposed by Irving Fisher, backed by a diversified index of commodities rather than a single precious metal. The same commitments would be required, holding the basket as backing of the cryptographic ledger and freely buying and selling to maintain a fixed price against the index.

But the case for the mutualised monetary ledger proposed in this chapter does not rest on such a return to gold or a commodity standard. The goal of avoiding state interference in the money supply, could arguably also be achieved by what are now fairly standard institutional safeguards, along much the same lines as those developed over the past four decades to support central bank independence in the setting of interest rates. For example a politically independent committee could be responsible for determining the quantity of fiat money on the monetary ledger and the extent to which fluctuations in bank money creation should be offset by opposite changes in the stock of fiat money. Therefore, for reasons of political acceptability, any proposed shift to a gold or commodity standard should be sequenced later after the creation of the distributed ledger for money.

(b) 'free banking', with minimal limits on the establishment of banks and market discipline limiting the production of money and fiduciary media, possibly with no central bank at all

The mutualisation of deposit money allows a substantial reduction in the regulation of banks. It can also be seen as a simpler, lower cost and more practical version of the ring-fencing proposals of the Independent Commission on Banking (Vickers 2011) now partially implemented in the UK or of the controversial 'Volcker rule' in the Dodd-Frank act in the US. Six years after the Vickers report, the practical challenges are clear, the ring-fencing requires an extensive system of bank monitoring, especially on the funding of bank balance sheets. The Volcker rule is widely regarded as unworkable.

Under the proposal put forward here, obtaining a license for lending, without the accompanying right to issue money on the mutualised ledger, could be made available fairly freely subject only to fairly modest requirements on quality and experience of management. Such initiatives would be like any other investment funds, with some need for protection for investors, especially when offered to unsophisticated retail investors or borrowers, but the extensive panoply of current existing bank regulation is not needed.

The right to issue bank-money on the mutual ledger should require meeting higher standards, in particular some assurance that the overall quality of the balance sheet does not substantially threaten failure of repayment onto the ledger. But comparatively simple rules can suffice to accomplish this (in addition to the $x$-percent reserving). These rules can be the responsibility of the industry to protect other banks. For example there might be a maximum limit on the ratio of bank 
monetary deposits to total bank assets .e.g of $50 \%$ or $60 \%$, a ratio that would be easily complied with by existing well established banks, low enough to prevent start up banks pursuing a short term gamble against the protection of the ledger.

The only free-banking proposal that is not directly supported by the mutual distributed ledger is the Hayek proposal for competition amongst commodity-backed currencies, but as already discussed this could conceivably still emerge through alternative private sector ledgers.

(c) limitations on the production of fiduciary media

This can be achieved imposing an $x$-percent reserving requirement, with the value of $x$ chosen to achieve an appropriate balance of flexibility in the supply of money that is achieved by allowing market driven bank creation of money against the instability that arises when banks do not take into account the impact of unsustainable money and credit expansion on the economy as a whole. Initially $x$ can be chosen to be fairly large, in order to avoid an uncomfortable funding lacuna for banks and an undesired credit contraction. Over time $x$ might be reduced to promote stability.

There are many further issues here about the supply of bank created money that can explored further beyond the discussion provided in this chapter. One possibility would be treating reserves as tradeable licenses, using a cap and trade to internalise unpriced externalities (Milne 2013; Stein 2012).

(d) avoidance of all forms of state subsidy and support for banks

This is achieved by ensuring that, after moving all forms of money onto a mutual distributed ledger, state support to banks is denied or strictly limited, even in a systemic financial crisis. A bank that faced difficulties in funding itself would first call on a limited opportunity for collateralised borrowing from the central bank (or perhaps better yet a bank clearing house). Depending on the regulations agreed by the industry for itself, there might be some possibility of suspension of repayment of short term money market borrowing for a limited period. Once these opportunities - which create time for either an acquisition or an orderly resolution - are exhausted, then the bank would face liquidation.

This in turn means that bank shareholders and behind them holders of bank debt, become the sole absorbers of bank risk. State support, beyond very limited provision of money market liquidity, is unnecessary. When banks are liquidated monetary transfers are not interrupted.

Removal of state support requires that retail depositors, who want to make term deposits in return for interest income, are no longer protected by state backed deposit insurance. As a consequence these loans to banks - which is what a bank term deposit is -- would likely be secured on individual bank assets, as is the case for the emerging practice of P2P or market place lending. Any deposit insurance would be entirely private sector. Retail investors would of course be well advised to diversify their investments and consider carefully their risk exposure, but this is not different than the situation which arises in any form of retail financial investment, short or long term.

It will though remain politically difficult to entirely avoid state support for banks in an extreme systemic financial crisis. Allowing a large proportion of banks to fail, even when money holdings and payments are not affected by bank failure, would be very disruptive for the provision of credit and hence for economic recovery. For this reason in an extreme crisis it is likely that only some banks not all - would be allowed to fail. Even then bank shareholders must not be bailed out. 


\section{Bank payment without settlement}

The previous section has set out the proposal for reform of monetary arrangements of this chapter and discussed how it can achieve the objectives of Austrian monetary thinking. This section examines the operational detail of the proposal, showing how the execution of payments using bank transaction deposits on a mutual distributed ledger no longer requires settlement.

\section{The evolution of bank payments and settlement: a short historical review}

As a preliminary to this discussion some historical perspective is in order, in order to make the key point that settlement is not an inherent and indivisible aspect of payments. For example non-bank payments using notes or coin, the physical transfer of money, is final payment. Some bank payment instruments do not require settlement either. Historically, where not prohibited, banks often issued their own private notes which could be presented for redemption in non-bank money i.e. precious metal or coin. These privately issued bank notes passed from hand to hand and were used in payment without requiring transaction by transaction settlement. Similarly bills of exchange - i.e. documents issued by merchants promising to pay a stated sum of money at a stated future date when 'accepted', i.e. the payment guaranteed by a bank, circulated as a form of bank endorsed money. Even today 'endorsed' cheques sometimes circulate as bank money without need for transactions settlement.

Interbank settlement emerged as a response to historical circumstance and technological change. Holding money in a bank rather than as precious metal, notes or coin offers advantages of both convenience and security. Even if the money must be withdrawn in order to make payments, fractional reserving by individual banks allows deposit-taking banks to provide monetary services with less opportunity cost from holding the unremunerated medium of exchange. Further convenience and cost reduction can then be achieved through payments that transfer directly from bank to bank, without requiring withdrawal at all. These efficiencies are maximised when the assets used for settlement can be centralised.

From the earliest history of banking, bank-to-bank payments have been possible through one bank holding a bilateral clearing account with another, the balances eventually and as necessary settled by transfer of a non-bank money. ${ }^{19}$ Something similar to this arrangement continues today in international correspondent banking, where a bank can provide its customers with payment facilities outside its own domestic realm of business by holding a correspondent account with another bank overseas.

In the $18^{\text {th }}$ and $19^{\text {th }}$ century such correspondent relationships were also an important part of domestic bank payments, with smaller regional or country banks holding accounts with institutions in financial centres. Examples include English and Welsh country banks holding accounts with clearing banks in London and local banks around the United States holding accounts with money centre banks in New York, Chicago and other 'money centres'.

During the later $19^{\text {th }}$ and $20^{\text {th }}$ century these bilateral correspondent relationships evolved into the now standard centralised holding of bank reserves as deposits with a central bank used for settlement of bank payments. Under the gold standard as first established in the UK with the restoration of convertibility of Bank of England notes in 1821 these reserves were claims on gold.

\footnotetext{
${ }^{19}$ One early example described by (De Roover 1942)is that of the money changers operating in Bruges from the late $13^{\text {th }}$ century, whose activities are recorded by the preservation of two of their account books. As De Roober, page 63 , describes oral instructions for bank to bank payments could be financed by a corresponding debit or credit to a clearing account held by one bank with the other.
} 
Holding reserves of gold centrally supported a money market allowing banks to lend reserves amongst each other (in London the 'discount market' which operated by the sale and purchase of discounted bills of exchange) and hence made the most efficient use of limited metallic reserves.

A related parallel development was the growth of centralised cheque clearing. For example in London a formal bank cheque clearing organisation was established by 1833 , allowing cheques between a group of banks to be periodically collected together and sorted in order that a large number of payment instructions could be settled together with a few interbank payments. From 1854 - with the volume of cheques cleared rising rapidly -- the London cheque clearing was settled through transfers of deposits at the Bank of England.

This shift to settlement of bank cheque payments using central bank deposits was the first step in the evolution from a pure gold standard in which domestic and international reserves were held as gold specie and coin, to a gold-exchange standard in which reserves were instead claims convertible into gold. A further development was a decline in the use of gold coin in day-to-day payments replaced by token moneys (state issued notes and coin in which the metal content was worth much less than the face value) and bank payments.

The shift to monetary exchange using token money, paper notes and bank deposit instruments settled in central bank reserves, facilitated the replacement of metallic monetary standards by 'fiat' standards in which the reserve assets were no longer even convertible into gold. This final outcome was reached with the eventual final and permanent abandonment of convertibility in the 1971 breakdown of the Bretton Woods fixed exchange rates amongst the industrial countries (after earlier abandonments of convertibility in 1914 as a consequence of the fiscal pressures of war finance and in 1931 during the international financial crisis of that year).

A further stage in the evolution of bank payments and settlement over the past half century has been the shift from paper-based and manual processing (cheque, giro, manual teller services for deposits and withdrawals) to the automated processing of a wide range of electronic and card payments in use today. This automation has supported another key development: today as already discussed it is bank deposits rather than previous metal or government issued notes and coin which are effectively the medium of exchange; few adult citizens in developed countries are now without bank accounts, even those who rely on state benefits as income are nowadays paid electronically. Associated with this shift has been the widespread provision of bank deposit insurance, with an explicit or implicit state backing. Nowadays it appears to be a political imperative on government, regardless of where they are on the political spectrum, to protect the money held by citizens as bank deposits. Limiting the exposure of the taxpayer to bank losses then requires close regulation and supervision of banks in order to limit their risk-taking.

The proposal of this chapter for decentralising the medium of exchange by putting all forms of money used in payments, bank transaction deposits together with notes and coin, on a single distributed ledger is a further technological development that can reverse the inexorable shift of responsibility for the provision of money and credit from the private to the state sector. It does so by removing the need for centralised settlement and provision of liquidity. This centralisation was a necessary feature, when bank deposit payments were paper based and took time to execute. Nowadays when payments using deposits are effectively instantaneous such centralisation is no longer necessary.

Such decentralisation on its own leaves one issue unresolved: if the medium of exchange is not remunerated, then there will always be an incentive for private sector provision of substitutes for 
the medium of exchange leading to a re-emergence of fractionally reserved banking. Two solutions are available to prevent this. One is to provide required remuneration of ledger money at a similar rate of interest as that on short term government bonds. Banks would then gain little commercial advantage from fractional reserving because the cost of funding of loans would be similar whether obtained from the ledger or from term deposits and money markets. This though has the disadvantage of undermining the existing business model of banking.

The alternative arrangement developed here, in order to ensure the industry welcomes the new arrangement, is to continue allowing banks to create money, on a temporary basis, in response to market demand. They do this by pledging loans to the ledger in return for the creation of money on the ledger. This is in effect a form of securitisation and the possibility of abuse can be protected using a variety of methods, many familiar from existing practice in asset backed securitisation. This arrangement and implications for banking and bank regulation are described in the next section.

\section{Settlement of bank payments in central bank reserves}

The overwhelming proportion of payments by value in developed countries are transfers of money from one bank account to another. A variety of instruments and payment schemes are available to execute these bank to bank payments. ${ }^{20}$ These all debit the bank account of the sender of money (the 'payer') and credit the bank account of the recipient of the money (the 'payee'). If the two bank accounts are held at different banks then the payment also requires a matching interbank settlement i.e. a transfer of the same value from the payer's to the payee's bank. ${ }^{21}$ Nowadays this settlement is almost always in central bank reserves.

While arrangements for bank payment and settlement are a fundamental part of the institutions of money and banking, they attract little attention either in money and banking textbooks or in the research literature. This section provides a short description of bank payment and settlement, and then describes how these arrangements are altered under the proposal of this paper i.e. using decentralised cryptocurrency technologies to remove the need for centralised settlement of bank payments and so clearly separating monetary deposits from potentially risky retail investment in banks. The section is completed with a short historical review of the evolution of bank payments and settlement, arguing that present arrangements using settlement in central bank reserves are a historical legacy necessary when providing payment facilities on bank deposits under older paper based or central server based technologies, but no longer required when payments are decentralised.

Figures 1 illustrates the operation of our current monetary arrangements, in which bank transaction deposits are used as the medium of exchange and settled in central bank reserves. The right hand panel is a simplified consolidated balance sheet for the non-bank private sector. Bank deposits include both transaction deposits used for making payments and other term or saving deposits, though the dividing line is not clear-cut for example savings deposits that allow immediate withdrawals can be regarded as money.

\footnotetext{
${ }^{20}$ For example in the UK a bank to bank payment can be made using the traditional paper instrument the cheque using the cheque and credit clearing scheme (CCCS); through a variety of instructions (direct debit, standing order, bulk payment instructions) via the bank automated clearing system (BACS), a card payment via either the Visa or Mastercard systems; an immediate direct online or telephone instruction via the faster payments scheme (FPS) or using the large value real time scheme( CHAPS).

${ }^{21}$ Settlement can be either at the same time the payment is made i.e. when the payer's account is debited and the payee's account credited ("gross settlement") or later ("deferred settlement"). If settlement is deferred then until it takes place the payer's bank has a liability for subsequent settlement to the payee's bank.
} 
Figure 1: fractional reserved banking with central bank settlement

\begin{tabular}{||l|r|}
\hline \multicolumn{2}{|c|}{ General Government/ Central bank } \\
\hline \multicolumn{1}{|c|}{ Assets } & Liabilities \\
\hline Real assets & Reserves \\
\hline C bank repo & Notes \\
\hline \multicolumn{2}{|c}{ Bonds } \\
\hline \multicolumn{2}{|c}{} \\
\hline
\end{tabular}

\begin{tabular}{||l|r|}
\hline \multicolumn{2}{|c|}{ Commercial banks } \\
\hline \multicolumn{1}{|c|}{ Assets } & \multicolumn{1}{c|}{ Liabilities } \\
\hline Bank Loans & Deposits \\
\hline Reserves & C bank repo \\
\hline Money market & Money market \\
\hline & Bonds/ Equity \\
\hline
\end{tabular}

\begin{tabular}{|l|l|}
\hline \multicolumn{2}{|c|}{ Non-Bank private sector } \\
\hline \multicolumn{1}{|c|}{ Assets } & \multicolumn{1}{c|}{ Liabilities } \\
\hline Real assets & Bank loans \\
\hline Bonds/ Equity & \\
\hline Deposits & \\
\hline Notes & \\
\hline
\end{tabular}

The middle panel shows the balance sheet of commercial banks. There are many competing commercial banks providing monetary deposits and payment facilities to the non-bank private sector. A deposit paid from Bank $A$ to Bank $B$ is settled through a matching transfer of reserves from bank $A$ to Bank $B$. If Bank $A$ loses reserves from an outflow of deposits, it can replenish them by money market borrowing; or by issue of bonds or equity purchased by the non-bank private sector using deposits from other banks.

The left hand panel is a consolidated balance sheet of general government and the central bank. This presentation highlights the role of central bank reserves (deposits with the central bank) as a source of government funding, something that was a principal reason historically for governments chartering central banks and has again become important with the policies of quantitative easing adopted since the 2007-2008 global financial crisis. There is though a major difference from central bank funding of government in the $18^{\text {th }}$ century and today: then the central bank deposits could be withdrawn by conversion into specie, now central bank reserves are inconvertible and can only be transferred to other banks as settlement of bank payments.

Figure 1 highlights a key aspect of our monetary arrangements that blocks widespread acceptance of Austrian monetary ideas. Central bank reserves are not the medium of exchange. They are not held by the private sector and so not used for payments. Central bank issued notes are held by the private sector and are used for payments; but notes are supplied on demand as a substitute for bank deposits. The original Misean analysis of the medium of exchange and money substitutes has reversed, it is now bank deposits that are the medium of exchange and central bank issued notes that are the money substitute.

This would not be such a significant change were it not for the accompanying fractional reserving of bank deposits. Were bank transaction deposits backed, one for one, by central bank reserves, i.e. if we had 100 percent reserving, then state backed fiat currency would still be the ultimate medium of exchange. But bank reserves are fractionally reserved so it is commercial bank deposit liabilities not central bank liabilities that have evolved today into the medium of exchange.

Fractionally reserved banking requiring, in turn, a central bank that stands ready to provide 'liquidity' i.e. additional central bank reserves, in order that bank payments can be settled and bank customers do not lose access to their holdings of the widespread accepted medium of exchange. This has been reinforced by the introduction of extensive state backed deposit insurance, first in the US in the 1930s, then worldwide from the 1970s onward. Thus Austrian proposals - for removing the support of the state for the banking system and restricting fractional reserved banking - are perceived not as a strengthening of monetary arrangements but rather as a politically unacceptable undermining of the medium of exchange. 


\section{Settlement no longer necessary}

The proposal of this chapter for using the technology of cryptocurrencies to put all money on a distributed ledger, allows them to function as a medium of exchange without the need for settlement in central bank reserves. An intuition that can help with understanding this point is recognising that demand for liquidity from settling interbank payments is required only by individual banks, not by the monetary system as a whole. ${ }^{22}$ Consider in Figure 1 the hypothetical situation where the monetary system consists of a single bank -which is also the note issuer - instead of several competing banks and a note-issuing central bank. There is then no need for settlement and thus no requirement for liquidity for settling payments between banks and indeed no need for a separate central bank.

While it would never be desirable to have only a single bank - such an institution would have unacceptable market power - it is possible, using the technologies of cryptocurrencies, for all money including monetary deposits to be held on a mutual distributed ledger instead of on bank balance sheets. Moreover, unlike proposals for 100 percent reserving, this need not result in a major loss of funding for bank balance sheets. Figure 2 illustrates how this is possible.

Figure 2: Fractional reserved banking without settlement using distributed ledger

General Government/ Central bank

\begin{tabular}{|l|r|}
\hline \multicolumn{1}{|c|}{ Assets } & Liabilities \\
\hline Real assets & Bonds \\
\hline Repo to banks & Money market \\
\hline Cryptocurrency & Notes 100\% backed by \\
\hline \multicolumn{2}{|c|}{ cryptocurrency (off balance sheet) } \\
\hline
\end{tabular}

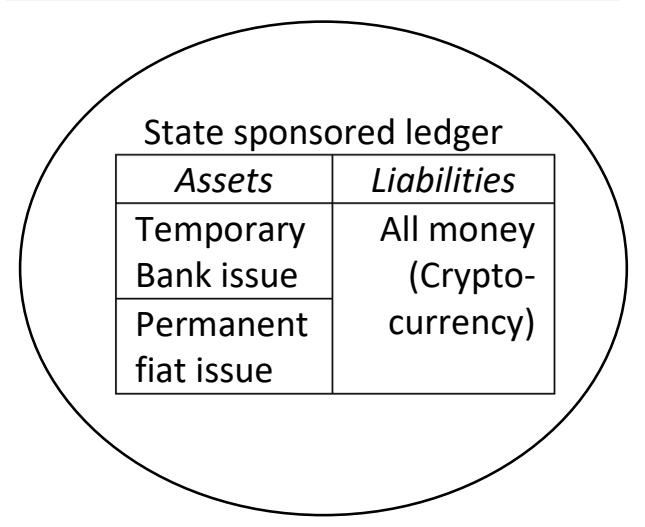

Commercial banks

\begin{tabular}{|l|r|}
\hline \multicolumn{1}{|c|}{ Assets } & \multicolumn{1}{c|}{ Liabilities } \\
\hline $\begin{array}{l}\text { Loans pledged } \\
\text { to ledger }\end{array}$ & $\begin{array}{r}\text { Liability to } \\
\text { ledger }\end{array}$ \\
\hline Other loans & Time deposits \\
\hline Money market & Money market \\
\hline Cryptocurrency & C bank repo \\
\hline \multicolumn{2}{|c|}{ Bonds/ Equity } \\
\hline \multicolumn{2}{|c|}{ (off balance sheet) } \\
\hline
\end{tabular}

Non-Bank private sector

\begin{tabular}{|l|l|}
\hline \multicolumn{1}{|c|}{ Assets } & \multicolumn{1}{c|}{ Liabilities } \\
\hline Real assets & Bank loans \\
\hline Bonds/ Equity & \\
\hline Time deposits & \\
\hline $\begin{array}{l}\text { Cryptocurrency } \\
\text { and notes }\end{array}$ & \\
\hline
\end{tabular}

The key difference from current arrangements shown in Figure 1 is that all money is now placed on a state sponsored mutual distributed ledger, shown as the oval on the lower left of the figure. Note that there is only one type of money, whether issued by the state (fiat) or by banks all money is now held on the ledger. The holder of money has no need to distinguish whether their money holdings were 'originally' created by permanent fiat issue or by temporary bank issue. ${ }^{23}$

\footnotetext{
${ }^{22}$ What about international transactions? Again, provided the exchange rate is freely floating, there can be no liquidity shortage for the banking system operating within a single currency area.

${ }^{23}$ Technically it would be possible to trace back the history of transactions on the ledger to determine the proportions of fiat and bank money of any particular holding of cryptocurrency, but there is no economic reason for this making any difference in the acceptability of money in exchange or technical advantage of using
} 
An analogy can be made between the arrangement shown in Figure 2 and the division made by the 1844 Banking Act of the Bank of England into the note issue and banking departments. The state sponsored ledger corresponds to the note issue department. A banking division of the central bank borrows on money and bond markets, holds cryptocurrency and lends using repo to commercial banks. The analogy is though not exact. Figure 2 is presented on the assumption that there is a stateowned central bank whose balance sheet is then consolidated with that of general government. In 1844 the Bank of England, while state privileged, was privately owned.

Figure 2 deliberately shows the sponsored ledger as separate from the consolidated balance sheet of general government and the central bank. This is done in order to emphasise that if the government or the 'banking' division of the central bank borrows in financial markets and offers collateralised lending to commercial banks and were then to default on their borrowing this would not affect money and payments.

Some further features of this arrangement as envisaged here are as follows:

- While state money issue is permanent and irrevocable; bank money issue is temporary, backed by a promise of repayment secured through bank loans pledged to the ledger. This provides the necessary elasticity in the supply of money which, historically, has meant that commodity based monetary standards have in practice tended towards exchange standards with a combination of commodity and bank money.

- The ledger should not be accessible as a source of funding for long term loan commitments e.g. mortgages relying on collateral values for repayment. The loans pledged must be amortising loans with a maximum maturity of perhaps five years.

- Notes, while still managed and issued by the central bank are now fully backed by cryptocurrency, the central bank is obliged to purchase or borrow cryptocurrency in order to issue notes. The notes and the cryptocurrency backing are now off-balance sheet.

- Commercial banks no longer hold reserves with the central bank reserves at all. Commercial banks must hold reserves of cryptocurrency, in order to repay maturing liabilities (time deposits, money market borrowing, central bank repos) but these are held directly with the mutual distributed ledger and are no longer part of the infrastructure of payments.

- The non-bank private sector no longer holds or uses bank deposits as money. All money is now on the ledger. To provide customers with payment facilities, commercial banks now provide 'wallet' services, i.e. security, accounting and other money management services for holders of cryptocurrency. From the perspective of the user, little changes, they continue to use their existing banking channels - branch, online, telephone, card payments - exactly as before. The difference though is a transformation of the back office, payment instructions are now instructions for transfer of ledger money.

- Cryptographic security ensures that that the ledger operates as a totally secure and immutable record without any need for a central authority or risk of loss or failure. The supporting distributed software shared by government and private sector ensures its integrity.

this information in payment processing. To fully enforce the equivalence of money on the ledger, a legal prohibition might also be imposed on using information on the proportion of fiat origin as a criteria for acceptance in payment or simply by making all ledger money legal tender. 


\section{Implications for banking and bank regulation.}

This section describes the changes in banking and bank regulation made possible by the decentralisation of money proposed in this chapter. It begins by describing two protections preventing banks from using their authorisation to issue money on the ledger for excessive expansion of money and credit. It then describes how responsibility for bank regulation can shift from the state to the banking industry and the opportunity for withdrawal of state support for banking through scaling back the availability of a lender of last resort and removal of the bank safety net, whether explicit deposit insurance or the implicit bank safety net. Finally it discusses prospects for adoption.

\section{The triple lock: ensuring repayment of bank money on the ledger}

The prevention of unsustainable expansions of money and credit require, with a very high degree of probability, that the commitment to repay bank created money onto the ledger (as illustrated in Figure 2 ) is honoured and there is never a call on the permanent creation of money on the ledger to repay loans.

The first obligation of repayment is the same as with existing bank loans, the loan contract agreed between the bank and the borrower obliges repayments that can be made directly onto the ledger, extinguishing the money previously created. The cryptographic coding will automatically take the monetary payment at the agreed time, determined if required to the nearest minute or second. The borrower will default if, at that moment, they have insufficient ledger money associated with their node on the ledger from which the commitment to repay principal has been made.

This leads to an issue not fully pursued in this chapter, which is whether individuals and companies including both non-bank corporates and banks, can create more than one node on the network. In order to enforce repayment disciplines it would seem appropriate to have only node for every legal entity.

This is a first line of defence against the possibility of the failure to repay money borrowed off the distributed ledger. A second line of defence is the underwriting of the loan obligation by the bank, based on its credit assessment of the borrower. The bank as well as the customer has its own node on the network for its own holdings of cryptocurrency. If the borrower fails to repay principal as agreed, then the algorithm coded on the ledger automatically takes the principal repayment from the bank to pay down the borrowed money on the ledger. Banks would likely have multiple nodes on the ledger, each corresponding to one of the many legal entities within a typical banking organisation, but there should then be an obligation that any call on payment to the ledger, which cannot be completed by a bank subsidiary because it has insufficient money on the ledger, will be fulfilled instead by a payment out of money held by the bank holding company. These bank payment obligations - along with those of the borrower - should all be coded into the distributed ledger and deductions automatically taken by the ledger algorithms, with conditional branching: if not paid by the borrower, then by the bank subsidiary, if not by the bank subsidiary then by the bank holding company.

If the bank also has insufficient money on the ledger for the required repayment i.e., if its holding company and subsidiary holdings of money on the distributed ledger has fallen below the required repayment at that point in time, then a third line of defence comes into play. Now the coding of the ledger calls on all other banks to make the repayment onto the ledger, most obviously with an obligation to make payment in proportion to the amount of money they have outstanding on the ledger at the time the money was first created. Once again this is all undertaken automatically, using 
the algorithms of the ledger ("smart contracts") without the need for any administrative intervention by either banks or regulators. At the same time the bank that has failed to support its credit underwriting commitment will be entered into resolution. The details of this process are not considered here, but this cannot be undertaken automatically on the monetary ledger without administrative and regulatory intervention, because it involves all the other bank assets and liabilities that remain on a bank's balance sheet. Still one would expect that this resolution process would involve a suspension of various claims, of both debt and equity holders, and a new temporary management with responsibility for determining how to restore the bank to a situation when it can once again command sufficient resources to maintain a sufficient balance of money on the ledger to continue its business and meet any other regulatory requirements.

A further appropriate protection for ensuring confidence that money-financed bank loans are repaid onto the ledger will be to give the claims on the ledger priority over all other creditors in bank liquidation, including even the tax authorities.

\section{Applying $x$-per cent reserving to limit fractionally-reserved monetary deposits}

Even with the triple lock there will be a concern that money-financed bank lending will encourage unsustainable expansion of both money and credit. Bank-money on the ledger is still fractionally reserved, providing banks with a low cost source of funding. Moreover, allowing banks to mutualise their monetary funding, removes an important current market discipline on bank monetary creation.

Under competitive fractionally reserved banking, banks must allow for the fact that when they create monetary deposits through lending, they will then subsequently lose some of these deposits to other banks and so - if they expand much faster than other banks - will have to shift the balance of their funding from relatively inexpensive monetary deposits to relatively expensive term deposits and money and security market borrowing. Under the proposed mutualisation of monetary deposits of this paper, this discipline vanishes. To the extent that the costs of overexpansion then fall on other institutions the result can be excessive expansion of money and money financed-credit.

An additional offsetting discipline can be imposed by requiring banks, when creating money on the ledger as in Figure 2, to commit $x$-percent of their own money to the funding of the loan. The actual requirement could lie anywhere between the two extremes of -0-percent reserving (banks need keep not reserves against money created against a loan) to 100-per cent reserving (banks can no longer create money at all, all loans must be financed by borrowed money).

This is a form of 'overcollateralisation' of the kind already widely used in asset-backed securitisations. Such overcollateralisation also makes it even less likely there will ever be a call on the ledger to finance bank loan losses on any large scale. Making $x$ too large however could limit the supply of credit. Arguably there are some positive externalities from encouraging bank supply of credit, especially for short term business lending and in areas such as trade and working-capital finance. Both research and practical experience will have to be taken into account in choosing the appropriate level for $x$.

Limiting fractional-reserved banking in this way will not just reduce monetary financed bank lending, it will also restrict the availability of money for the required refinancing of short term funding, whether on-balance sheet by commercial banks or by shadow banks who are unable to create money on the ledger.

The macroeconomic consequences of the proposal of this chapter - including $x$-per cent reserving need a great deal of further study and will benefit from more formal modelling of the externalities arising both in bank lending together with additional externalities from mutualisation of bank 
liquidity risk. Such externalities - both positive and negative - arise easily in payments networks and are only increased by putting all money on a distributed ledger. Further analysis is needed to help determine an appropriate level of the $x$-percent requirement for internalising these externalities. ${ }^{24}$

\section{Prudential regulation becomes an industry responsibility}

The free riding problem arising from the externalities in money creation on the distributed ledger is a key issue on which the practicality of this proposal stands or falls. Two mechanisms for internalising these costs have been described: (i) the triple lock; -- underwriting by first the borrower, second the bank, third the entire industry; and (ii) $\mathrm{x} \%$ reserving requiring banks to put some of their own money as overcollateralisation of money created on the ledger.

Despite these protections, it is conceivable that commercial banks can exploit the opportunity for creating money on the ledger by financing loans with a significant probability of the burden of repayment falling on others. Some form of prudential regulation will be still necessary for banks that issue money on the ledger, in order to 'internalise' this economic externality and prevent free-riding.

Since, under the 'triple-lock' it is industry that is the final line of defence against abuse of the ledger, this in turn suggest that there should be an accompanying move from state to self-regulation, with the industry taking over all responsibility from government for micro-prudential regulation. This is because industry makes repayment of defaulted loans pledged to the ledger and subsequently stands ahead of the taxpayer in exposure to credit risk on the ledger. Therefore it is the industry not government that should agree rules for loans put on the ledger and for the capital adequacy rules applied to banks that use the ledger for funding their loan.

All elements of state support for the banking industry can be withdrawn. In particular there is no longer any need for state backed insurance of bank deposits, which can immediately cease.

Transaction deposits are no longer at any risk of loss. Term deposits are credit risky loans to banks, which might be insured by an industry scheme, but should make explicit that this insurance is private sector without state backing and in extreme situations with widespread bank losses the compensation fund may be exhausted and not be able to fully protect depositors.

What might industry choose to do? This is their responsibility, but they might for example require some form of external rating by a credit rating agency (which would in turn likely require the loans to be packaged as pass-through securitisations) and also capital rules for the banks that securitise, since these are securitisations with explicit sponsor support, not balance sheet remote). Since their concern is with the off-balance commitment to repayment of money to the ledger, not the repayment of on-balance sheet bank liabilities, they are likely also to set some maximum ratio of money created on the ledger to total bank assets.

A key point here is though that because the industry is setting these capital rules for themselves, the externality being internalised at industry level, it can be the industry that sets these rules. No longer will they be able to argue that microprudential regulation is an unacceptably burdensome constraint on their own business (which is what industry thinks of the current Basel III and Dodd-Frank regulations). ${ }^{25}$

The state steps back entirely from responsibility for micro-prudential regulation. There are in effect two types of banks: banks who issue money on the distributed ledger; and those who do not

\footnotetext{
${ }^{24}$ See (Stein 2012) for discussion of the loan externality, related to the realisation of loan collateral in a crisis.

${ }^{25}$ For example the research and lobbying material of the institute for international finance

https://www.iif.com
} 
(including all non-bank lending institutions what can be collectively referred to as 'shadow banks'). Prudential regulation is no longer necessary for banks that do not issue money on the ledger: they should be subjected only to rules on customer protection and investor disclosure. In the case of money issuing banks all responsibility for additional microprudential regulation can be passed in its entirety from the state to the industry. Prudential regulators - e.g. the FDIC and the regulatory divisions of the Federal Reserve in the US, the PRA in the UK - can be abolished, or rather moved from being a government department to become industry governed self-regulatory organisations.

Government will still need to be in the background to ensure that self-regulation does not operate to restrict competition. The FDIC in the US and the PRA in the UK are privatised, but come under the oversight of the Department of Justice and the Competition and Markets Authority respectively.

The state could likely also retain a macroprudential responsibility, ensuring that the overall growth of money and credit does not threaten financial stability. The $x$-per cent reserving described below is the most obvious tool for them to carry out this task, though clearly changes would have to be infrequent and only after extensive consultation.

What about international financial regulation? The Basel committee, the BCBS, can also largely be abolished, but would retain some competition role -- making sure that banks from one country do not use their access to the ledger to gain an unfair competitive advantage in other jurisdictions -and perhaps on safety and soundness in foreign exchange markets (merging with the sister committee CPSS would be appropriate).

\section{Money markets and the role of the central bank}

Not all bank assets and liabilities are recorded on the mutual distributed ledger, far from it. Banks would continue to have debt and equity liabilities on their balance sheet, both short and long term borrowing and shareholder funds. Only monetary deposits are moved off-balance sheet onto the ledger. Banks would continue to hold on their own balance sheet loans that are not funded by money creation, securities and other assets. Only loans pledged to the ledger are moved off-balance sheet, with a conditional liability to repayment.

Banks still need to hold reserves of the cryptographic currency and continue to operate a treasury function, in order to manage the their own cash flows, arising from commitments to lend e.g. lines of credit and any default of loans pledged to the ledger as well as for repaying their own borrowings, whether retail and corporate time deposits or from money and security markets. Banks would participate actively in short term money markets, taking short term deposits or issuing tradeable money market instruments such as negotiable certificates of deposit, investing themselves in money market instruments.

What role then for the central bank? Would a central bank be needed under this arrangement at all? It will seem sensible, in order to promote its political acceptability, that when initially established the new arrangement should be as close as possible to what pertains today. The question of the role and operation of the central bank can then be addressed subsequently. In order to minimise the change in institutional arrangements the sponsored ledger could be set up as a division of the central bank, i.e. in analogy with the 1844 Banking Act.

There would though still be major changes in operation and responsibilities of the central bank:

- The 'banking division' of the central bank, since it would have lost its power of money creation, could potentially default (though since its balance sheet is supported by the state this default would presumably only happen in the context of a general government default). 
It would be essential that the ledger remained operationally fully separate of the rest of the central bank, in order to ensure that a general government/ central bank default did not disrupt money and payments.

- With central bank reserves no longer used for settlement of payments, the central bank, while continuing to be a major if not the most important participant in money markets both as borrower and as lender, would no longer have complete control over short term money market rates of interest.

- Monetary policy operations, instead of being conducted through control of interest rates, would be conducted by additions to the stock of irredeemable fiat money on the ledger by the ledger department of the central bank. This money would then become a source of funding for general government spending.

As a state owned, not private, entity considerable thought would have to go into defining the objective and governance of both the ledger division and the banking division of the central bank. Some preliminary thoughts on these can be given here, without claiming to provide a full and final analysis.

The ledger division will initially operate by following as an ultimate monetary target, the rate of inflation as already pursued by central banks worldwide. It will increase or slow down its permanent and irredeemable issue of fiat money on the ledger according to its views on how this will affect the rate of inflation in the short to medium term.

A primary continuing role for the banking division of the central bank will be its historically important role of providing funding for general government expenditure, especially at the short end of the maturity spectrum, and in facilitating the marketability of government debt.

A second major role for the banking division of the central bank would be support for short term markets in money and credit, especially in times of financial stress. The central bank can still hold its own potentially substantial reserve of the cryptocurrency, which it could lend to commercial banks against collateral as appropriate on occasion to help allay difficulties banks might face in refinancing themselves in short term money markets.

This raises the question of when and how the central bank should conduct such interventions. Monetary policy would be the responsibility of the ledger division of the bank, not of the banking division. The possibility of a 'panic', preventing even sound banks from borrowing in money markets, suggests that the central bank should be prepared, on occasion, to conduct discount window operations - lending at above market rates against good collateral to banks unable to fund themselves. At other times a desired level of holding of cryptocurrency would have to be determined that bears a large enough ratio to the level of bank money market borrowing to stem any incipient panic.

The central bank might also play some limited role - in effect a market maker - in short term money markets, lending to the market from its cryptocurrency reserves, in order to limit temporary short term spikes in money market rates of interest.

The execution of these responsibilities could possibly be supported, in turn, by allowing the central bank to also create money temporarily on the ledger, pledging good quality loans. As a government owned institution, this would conflict with the proposal put forward here for the triple lock, with private industry providing the ultimate guarantee on repayment to the ledger. Banking division money creation for the purposes of stabilising money and credit markets would have to be on an entirely different basis. Further analysis is needed to determine if any such power is really needed. 
The outcome of such a mechanism would be to economise on the need for the central bank to hold its own reserve of cryptocurrency. Since there are no real resource costs, the decision of to what extent the central bank creates and then holds cryptocurrency in reserve, or to what extent it is allowed to creating in an emergency, seem immaterial. All that matters is the total reserve, whether created in advance or only at a time of need. To avoid any suggestion that repayment of defaulted loans would become a state responsibility, it would seem best not to allow a state owned central bank access to the ledger.

Note that these mechanisms are all ultimately concerned with bridging shortages of credit availability, inability to replace credit is still a liquidity risk, but it is a risk that does not interrupt the payments system, at worst is will limit the supply of bank lending (but provided banks have retained some balance sheet capacity, profitable bank lending can still continue to be financed to some degree through money creation on the ledger).

\section{Resolution of failing banks and 'shadow banks'}

What about the resolution of money-issuing banks or other lending institutions ('shadow banks')? There are really two separate issues to be considered here. The first is the relatively easy challenge of dealing with the isolated failure of an individual institution, or of a small number of institutions, whether this occurs as a result of fraud, mismanagement or the materialisation of financial risk.

Such failures should be resolved in just the same way as the failure of a non-financial institution. If no buyer can be found to take over the institution so it can continue as a going concern, then it must be put into resolution, with all credit commitments suspended. If it is a money issuing bank then its ledger commitments and wallet services must be maintained (possibly with transfer of wallet services to another provider).

The isolated failure of even a large lender, accounting for say twenty or thirty percent of the provision of loan credit, should also still be perfectly manageable. Lending subsidiaries which continue to be profitable can be sold along with their assets and staff.

More difficult questions arise should failure or the threat of failure affect an even larger proportion of credit markets, something that could arise in the aftermath of an unsustainable expansion of credit. The arrangements proposed in this chapter will go a long way to ensuring that such an unsustainable expansion does not happen, but for this to be credible it must be clear that even in a systemic credit crisis state support will be far from automatic. More discussion is needed, but a sensible and practical response, in such a situation, will be to let the worst institutions with the largest credit losses go under, but provide temporary support through preferred equity investment for the remainder so that the credit market continues to operate in a systemic crisis.

\section{Prospects for adoption}

The operational rules proposed for the ledger are straightforward, but is adoption realistic? This subsection will argue that the new arrangements will impose minimal disruption on bank customers and be attractive to banks. Hence they are a politically realistic program of reform.

Might bank customer resist this proposal? From the perspective of bank customers this ledger will be operated in the background, with little impact on their day-to-day transactions. With such a scheme bank monetary deposits would then become 'wallet services', much the same as the wallet services currently provided for holding cryptocurrencies. They would help customers manage and use their cryptographic keys and execute payments. Assuming that the immutable ledger records transactions not balances, then wallet providers i.e. banks would also maintain records of account 
balances for customers. As illustrated in Figure $1 \mathrm{~b}$, it is only the original loan and repayment of principal that would be recorded on the distributed ledger. Associated interest payments would also be agreed in the loan contract, but these obligations do not involve repayment and extinguishing of money on the letter and so would be settled by monetary ledger transfers of the kind shown in Figure 1a rather than Figure $1 \mathrm{~b}$.

Tax and other obligations for payment to government would have to be settled in ledger money. While legal tender is no longer a major feature of monetary arrangements, the legal tender status which central bank notes have in many jurisdictions (i.e. the legal obligation to accept bank notes in settlement of debts) could be extended to money on the ledger. This would provide further incentives for bank customers to accept the transition of money onto the ledger.

One possible objection to the ledger is that placing all fiat and bank money on a mutual distributed ledger would require the abolition of cash transfers and their associated anonymity. This is not a valid objection. The use of cash is a quite separate issue unaffected by the transfer of fiat and bank money onto the ledger. Banks notes would continue to be central bank liabilities and would still be issued as now, on demand, in exchange for money held in transaction deposits, most often through an ATM withdrawal. The only change is that all notes and coin would now be fully backed by money on the ledger.

Banks would continue to provide the full existing range of other banking services to customers. Payment instructions would not be altered (only the subsequent processing of those instructions). Loans could be either money financed or they could be financed directly using the bank's own money. Where banks provide lines of credit, rather than loans with fixed repayment schedules, then they will need to maintain sufficient balances of ledger money, or sufficient loan assets acceptable as collateral on the ledger, to allow customers to draw down on their credit lines.

The major perceived difference for bank customers is the changed status of non-monetary bank deposits without transaction facilities. A fixed term deposit with a bank must be presented and understood as a loan to the bank, money which the bank is not keeping but itself lending on to other customers. From the customers perspective such a loan to a bank or an investment in a non-bank alternative lender ( $a$ 'shadow bank' or a marketplace lender) will be very much the same. State support of these deposits, in the event of failure of the deposit insurance fund being exhausted, will be forthcoming only in the event of a complete systemic collapse of the banking industry and even then only for some institutions not all.

Banks though will be able to provide some investments that cannot be so easily provided by nonbank lenders ('shadow banks') without ability to create money on the ledger. These are savings deposits with an option for early withdrawal and lines of credit that can be drawn down by the customer as they are needed. They would have some comparative advantage in providing these deposits because of their access to the ledger for money creation.

Might banks resist such a proposal? They will be concerned about the costs of reengineering their payment systems, but their attitudes must depend on the entire package of reform not just the creation of the ledger. Banks could anticipate a substantially reduced burden of regulatory compliance. They would also obtain a new source of revenue as they take over the role of central banks providing an elastic increase in monetary deposits needed, for example, when there are large demands for means of payment arising for either seasonal reasons or because of large financial market transactions. The ledger would also offer banks new tools for monitoring borrower repayment. 
Could banks avoid using the ledger and still provide their customers with payment services? This would require on setting up competing payment schemes with accompanying arrangements for settlement, i.e. setting up a banker's bank or clearing house replacing the existing central bank role of supplying reserves for settlement of payments. Such off-ledger payment arrangements are conceivable and need not necessarily be outlawed, but implementing them would require extensive investment in underlying operational systems - at exactly the same time as substantial investment is also being made in on-ledger operations - as well and agreement on the alternative asset for settlement and arrangement between banks for provision of liquidity. Final judgement must be reserved but it seems unlikely that banks would 'vote with their feet' and en masse withdraw from the ledger.

It would be feasible and desirable to allow banks to substitute loans on the mutual ledger so that loan default and its management can be moved back entirely onto their own balance sheet. This would be recorded in the mutual ledger as two transactions, an existing loan being placed on the ledger at exactly the time when the troubled loan faces a potential default of principal repayment, thus fulfilling the bank's obligation to extinguish an entry on the ledger. The payment arrangements for any loans transferred onto the ledger would have to be set up appropriately at the time the original loan was made, to avoid costly administrative exchange with the borrower to change payment arrangements.

There is though one strong argument against adoption that will have to be given serious consideration. There will be obvious problems for borrowers who have taken on large debts anticipating the continuation of artificially low rates of interest for the foreseeable future. These are not an insignificant group. In the UK, Australia and other countries many households have taken out large mortgages in relation to their incomes at floating rates of interest and will be exposed to substantial financial stress, following the likely rise of market rates of interest following the ending of central bank control of overnight interest rates. Residential house prices are, in turn, likely to fall sharply. Another likely impact are falls in financial asset prices currently supported at artificially high levels by leveraged finance at low rates of interest.

This is not an argument against adoption, but rather an acknowledgement that the macroeconomic adjustment will be difficult and likely require some temporary state action to alleviate some of the worst burdens of repayment. But the alternative, of continuing with state domination of the process of money and credit creation have even greater costs, so this is a nettle that needs to be grasped. 


\section{Conclusions}

Austrian monetary economics draws our attention to fundamental problems caused by state incursion into the provision of money and credit. This incursion not only distorts incentives, it also has resulted in a failure to address the problems of unsustainable credit creation, maturity mismatch and asset mispricing that was behind the last global financial crisis and therefore threatens a future crisis of even greater severity. This could in turn undermine the market-based economic system that has supported the dramatic rise of living standards across the world over the past four centuries.

This chapter proposes a technological solution to this challenge, using cryptocurrency technologies to put all bank transaction deposits and fiat money together on a single 'mutual distributed ledger'. This can achieve Austrian objectives for monetary arrangements, supporting in particular an almost complete withdrawal of the role of the state in banking industry and the provision of money and credit, which will allow a market-based response to our current monetary and macroeconomic economic challenges.

This reform also has several desirable features, including:

- A proper match between customers perceptions ('my money' is kept securely and conveniently by a bank) and actual banking operations (the bank has no permission to use this money for purposes of its own)

- There is no longer a need for a state-backed deposit insurance to protect customer money held in banks (though private sector schemes for insuring returns on investments in banks or alternative non-bank lenders may be provided)

- Complete protection of bank money and payments from any interruption resulting from bank failure. Since all money is on the ledger, not on bank balance sheets, customer access to bank money and payments services can continue uninterrupted even while a failing bank is being resolved.

- No need for settlement of payments using central bank reserves and a substantial scaling back of central bank intervention in money and security markets (though the central bank remains a major participant and may play a role in promoting orderly market conditions).

- Banks continue to engage in temporary money creation in order to finance short term needs for credit, for example from seasonal fluctuations or substantial financial market transactions, thus providing a private sector (but state supported) solution to the problems of ensuring a sufficient elasticity in the supply of money and credit

- Existing business models and payments arrangements are relatively unaffected, making this proposal more politically acceptable than Austrian policy ideas based on older technologies.

Despite these advantages, the changes proposed here are profound with some substantial economic losers - those who have relied on low cost state distorted finance for investment in real or financial assets. This means that they are unlikely to quickly attract widespread support and may only be taken seriously in policy debate, if this ever happens, only after a further future crisis makes it impossible to deny the shortcomings of current widespread state involvement in our arrangements for money and banking. 


\section{References}

Ali, R. et al., 2014a. Innovations in payment technologies and the emergence of digital currencies. Bank of England Quarterly Bulletin, p.Q3.

Ali, R. et al., 2014b. The economics of digital currencies. Bank of England Quarterly Bulletin, p.Q3. Andolfatto, D., 2015. MacroMania: Fedcoin: On the Desirability of a Government Cryptocurrency. Macromania Blog. Available at: http://andolfatto.blogspot.co.uk/2015/02/fedcoin-ondesirability-of-government.html.

Barrdear, J. \& Kumhof, M., 2016. The Macroeconomics of Central Bank Issued Digital Currencies.

Coskun, V., Ozdenizci, B. \& Ok, K., 2013. A survey on near field communication (NFC) technology. Wireless personal communications, 71(3), pp.2259-2294.

Dowd, K., 2014. New Private Monies: A Bit-Part Player?

Fung, B.S.C. \& Halaburda, H., 2016. Central Bank Digital Currencies: A Framework for Assessing Why and How.

Hayek, F.A., 1978. Denationalisation of Money-The Argument Refined,

Hayek, F.A., 1979. Free Market Monetary System, A, Ludwig von Mises Institute.

Hayek, F.A., 1937. Monetary nationalism and international stability, Longmans, Green.

Koenig, A., 2015. A Beginners Guide to Bitcoin and Austrian Economics., FinanzBuch Verlag.

Koning, J., 2014. Fedcoin. Moneyness blog. Available at: http://jpkoning.blogspot.co.uk/2014/10/fedcoin.html.

Milne, A., 2013. Register, Cap and Trade: A Proposal for Containing Systemic Liquidity Risk. Economics: The Open-Access, Open-Assessment E-Journal, 7(2013-7). Available at: http://dx.doi.org/10.5018/economics-ejournal.ja.2013-7.

Milne, A. \& Wood, G., 2008. Shattered on the Rock? British financial stability from 1866 to 2007, Available at: http://ideas.repec.org/p/hhs/bofrdp/2008_030.html.

Milne, A.K.L., 2016. competition policy and the financial technology revolution in banking. Digiworld Economic Journal, (103), pp.145-161.

Von Mises, L., 1953. Theory of Money and Credit, The Revised., Indianapolis: Ludwig von Mises Institute. Available at: http://cc10.aubg.bg/faculty/kpetrov/Other/Textbook Downloads/von Mises - Theory of Money and Credit.pdf [Accessed July 9, 2014].

Monetary Authority of Singpore, 2017. MAS working with industry to apply Distributed Ledger Technology. Media Release. Available at: http://www.mas.gov.sg/News-and-

Publications/Media-Releases/2017/MAS-working-with-industry-to-apply-Distributed-LedgerTechnology.aspx.

Nakamoto, S., 2008. Bitcoin: A Peer-to-Peer Electronic Cash System.

Redish, A., 2006. Bimetallism: An economic and historical analysis, Cambridge University Press.

De Roover, R., 1942. Money, banking, and credit in medieval Bruges. The Journal of Economic History, 2(S1), pp.52-65.

Schwartz, A.J., 1989. Banking school, currency school, free banking school. The New Palgrave: Money. London and Basingstoke, pp.41-49.

Selgin, G., 2015. Synthetic commodity money. Journal of Financial Stability, 17, pp.92-99. Available at: http://www.sciencedirect.com/science/article/pii/S1572308914000722 [Accessed June 7, 2015].

Skingsley, C., 2016. Should the Riksbank issue e-krona? Speech at FinTech Stockholm, 16 Nov 2016, revised 30 Nov 2016. Available at: http://www.riksbank.se/en/Press-andpublished/Speeches/2016/Skingsley-Should-the-Riksbank-issue-e-krona/ [Accessed April 15, 2017].

Stein, J.C., 2012. Monetary policy as financial stability regulation. The Quarterly Journal of Economics, 127(1), pp.57-95.

Taub, B., 1985. Private fiat money with many suppliers. Journal of Monetary Economics, 16(2), pp.195-208.

Vickers, J., 2011. Independent commission on banking: final report, 
White, L.H., 2014. The market for cryptocurrencies. 